\title{
EL COMANDO DEL LITORAL Y LA ACCIÓN ARMADA CONTRA EL RÉGIMEN DE LA RESTAURACIÓN CONSERVADORA EN LA PRIMERA MITAD DE LOS AÑOS TREINTA
}

\author{
The Comando del Litoral and the armed action against the conservative regime \\ in the first half of the thirties
}

\author{
Sebastián R. Giménez*
}

\begin{abstract}
Resumen
El presente artículo se propone como objetivo reconstruir la trayectoria seguida por un grupo militar revolucionario que a lo largo de la primera mitad de los años treinta intentó derribar a los gobiernos de Uriburu y Justo a través de alzamientos armados con epicentro en el litoral del país. Dicho grupo se denominó el "Comando del Litoral". A través del análisis de fuentes escasamente exploradas, en este artículo procuramos reconstruir las características principales asumidas por el Comando: presentamos a sus principales líderes y referentes, analizamos los motivos por los cuales éstos decidieron centrar su accionar en la región mesopotámica, reflexionamos sobre los vínculos que establecieron con sectores civiles y militares, examinamos las distintas incursiones armadas que llevaron a cabo, y, finalmente, en las conclusiones, realizamos una serie de consideraciones acerca de la índole de los vínculos que el Comando del Litoral entabló con la Unión Cívica Radical, partido al cual apareció muy frecuentemente asociado.
\end{abstract}

$<$ Comando del Litoral $><$ Radicalismo $><$ Movimientos revolucionarios $><1930-1935>$

\begin{abstract}
This article intends to reconstruct the path forged by a revolutionary military group which aimed to overthrow Uriburu and Justo's government during the first half of the thirties through armed uprisings with epicentre in the northeastern part of the country, by the river coasts. Such group was called Comando del Litoral. By analyzing uninvestigated sources (such as General Agustín Justo's archive) and little-known bibliography, this article seeks to reconstruct the main features acquired by the Comando: we present its main leaders and referents, and study the reasons that led the Comando to focus its moves in the Argentinian provinces of Entre Ríos, Corrientes, and Misiones. Besides, we reflect on the bonds established by the Comando with civil and military sectors, and examine the different armed raids carried out. Finally, in the conclusions, we give some consideration to the nature of the relationship the Comando del Litoral built with the UCR, to which it often appeared related.
\end{abstract}

$<$ Comando del Litoral $><$ Radical Party $><$ Revolutionary movements $><1930-1935>$

Recibido: 22/04/2014 // Aceptado: 20/5/2015

* Doctor en Ciencias Sociales (UBA), Magíster en Ciencia Política (IDAES-UNSAM), y Licenciado en Sociología (UNLP). sebasgim82@gmail.com. 


\section{Introducción}

Los primeros años de la década del treinta en la Argentina fueron testigos del surgimiento y desarrollo de una amplia variedad de grupos que intentaron derribar a los gobiernos surgidos de la revolución de septiembre a través del uso de las armas. El orden político instaurado luego del derrocamiento de Yrigoyen resultó, en efecto, en sucesivas ocasiones, desafiado y contestado por sectores que juzgaron ilegítimo el desplazamiento del viejo caudillo radical de la presidencia, y que creyeron que la única alternativa para terminar con el régimen surgido de la revolución setembrina era el recurso a la fuerza. De tal modo, en el período posterior al golpe de estado llevado a cabo por Uriburu y los militares nacionalistas, nuestro país asistió al surgimiento de agrupaciones "revolucionarias" que impugnaron los mecanismos institucionales vigentes, y que, paralelamente, promovieron soluciones drásticas para cambiar la correlación de fuerzas favorable a los sectores conservadores.

El presente artículo se destina precisamente a analizar a uno de los movimientos revolucionarios armados que surgieron en la primera mitad de los años treinta y que se propusieron como objetivo explícito derribar a los gobiernos de Uriburu y Justo. El caso que aquí estudiaremos será el del "Comando del Litoral": liderado por uniformados afines al radicalismo y opositores a la conducción de Agustín Justo en las Fuerzas Armadas. Este grupo se caracterizó por haber desarrollado, a lo largo de más de un lustro, una intensa actividad conspirativa, la cual tuvo como epicentro las provincias del nordeste del país (principalmente, Corrientes, Misiones y Entre Ríos), aunque reconoció también ramificaciones en otras regiones no sólo de la Argentina sino también del Uruguay y Brasil.

El objetivo de las páginas que siguen consistirá en reconstruir las características principales asumidas por el Comando del Litoral: presentaremos a sus principales líderes y referentes, analizaremos los motivos por los cuales éstos decidieron centrar su accionar en la región litoral, reflexionaremos sobre los vínculos que ellos establecieron con sectores civiles y militares, examinaremos las distintas incursiones armadas que llevaron a cabo, y, finalmente, y a partir de los elementos mencionados, realizaremos una serie de consideraciones acerca de la índole de los vínculos que el Comando del Litoral entabló con la Unión Cívica Radical, partido al cual apareció muy frecuentemente asociado.

Pretendemos con ello realizar un aporte significativo a la historiografía y las ciencias sociales de nuestro país. Los movimientos revolucionarios armados surgidos en los primeros años treinta han sido, en efecto, escasamente explorados. Ciertamente, tanto los trabajos que reconstruyen la dinámica general del devenir político argentino posterior al golpe de estado setembrino (Halperín Donghi, 2004; De Privitellio, 2001; Macor, 2001) como aquellos otros que centraron su interés en el accionar de la UCR (Persello, 2004) y de la corporación militar (Potash, 1986; Rouquieu, 1986), no dejan de tomarlos en consideración, en tanto constituyen un actor que influyó de modo decisivo en distintas coyunturas críticas. Pero en esos abordajes, los movimientos revolucionarios no son analizados en su especificidad, y sólo aparecen mencionados en los momentos en que su irrupción en el espacio público obliga a hacer referencia a ellos. 
Por otro lado, recientemente, han aparecido una serie de crónicas elaboradas por historiadores profesionales y no profesionales pertenecientes a los distintos lugares en donde ocurrieron los alzamientos revolucionarios, quienes decidieron narrarlos con el propósito de resguardar la historia local. ${ }^{1}$ En la medida en que recuperaron valiosos archivos, y que, a través de entrevistas realizadas a participantes directos de los acontecimientos, recogieron muy relevantes testimonios orales, esos estudios constituyen una insoslayable fuente de consulta. Sin embargo, estos trabajos suelen tener el déficit de que pocas veces trascienden el marco local, además de que, al concentrar la mirada en un acontecimiento en particular, no permiten reconstruir los procesos más generales que subtienden a los diferentes hechos de armas.

Por nuestra parte, al tomar como unidad de análisis un colectivo revolucionario y seguir su accionar a través del tiempo, pretendemos recomponer la dimensión diacrónica, ausente en otros trabajos. Asimismo, al vincular este colectivo con procesos más amplios, pretendemos que la reconstrucción de su trayectoria nos permita reflexionar sobre algunas cuestiones clave, como la relación entre revolución y democracia, y, más específicamente, sobre las razones por las cuales desde 1930 se tendió a desafiar la institucionalidad por la vía de las armas, generando con ello una fuerte inestabilidad en el orden político.

\section{Los referentes del Comando del Litoral}

No tenemos conocimiento exacto acerca de cuándo el Comando se conformó como tal. La única referencia al respecto es la realizada por Miguel Ángel Villalba, quien señala que se encontraba activo "desde 1930" (Villalba, 2012: 34). Los primeros indicios ciertos de su existencia encontrados por nosotros son sin embargo posteriores. Más allá de esas imprecisiones, se puede afirmar que desde principios de la década, y hasta por lo menos el año 1936, el Comando del Litoral tuvo una presencia activa en el escenario político de nuestro país, protagonizando una serie de levantamientos armados que involucraron a civiles y uniformados de Argentina, Uruguay y Brasil.

Sus principales líderes fueron Gregorio Pomar y Roberto Bosch. Ambos ostentaban, al momento de producirse la revolución setembrina, el grado de tenientes coroneles del ejército argentino. El primero de ellos había nacido en 1892 en Santa Ana, un pequeño poblado situado en el sudoeste de la provincia de Misiones. ${ }^{2}$ Sus padres eran oriundos de Corrientes, provincia en la que Gregorio Pomar, luego de egresado del Colegio Militar en 1912, desempeñaría la mayor parte de su carrera castrense. Mientras permaneció en las filas del ejército, Pomar tuvo ocasión de participar en hechos vinculados con la arena política y social del país: en 1916 fue designado para mediar en un conflicto de trabajadores ferroviarios en la localidad de Monte Caseros (Corrientes); asimismo, en 1918 actuó, ya con el grado de capitán, en otro litigio obrero en la localidad

1 Son dignos de mención, en este sentido, los estudios de Sánchez de Larramendy (1994), Castelán de Fraccia (1999), Ezcurra y Ezcurra (1998); Cesario (2004); González Rebolledo (2005); y Villalba (2012).

2 Los datos biográficos sobre Pomar fueron extraídos de Pereira y Parente (1990: 36-37) y Villalba (2012: 38-40). 
Giménez. El comando del litoral y la acción armada contra el régimen de la restauración conservadora en la primera...

de Las Palmas (Chaco). En ambas ocasiones arbitró a favor de los trabajadores, lo cual le valió el reconocimiento de sus pares y superiores, y fue un factor que gravitó para que años más tarde, al asumir Yrigoyen su segundo mandato, resultase nombrado edecán presidencial. ${ }^{3}$ El principio de la "justicia social" estuvo siempre muy presente en el ideario de Pomar; incluso, según su propio testimonio, esa bandera influyó en su decisión de abrazar la alternativa armada para derribar a los gobiernos conservadores que asumieron el poder en septiembre de $1930 .{ }^{4}$

Muy distinta es la trayectoria de Roberto Bosch, quien provenía de una familia tradicional de la elite porteña. Bosch ingresó al Colegio Militar de la Nación en el año 1897. A principios de la década del 10, luego de cumplidas algunas funciones militares en el país, se radicó en Alemania, donde realizó estudios de su especialidad. Allí lo sorprendió la Primera Guerra Mundial, a raíz de la cual hubo de regresar a la Argentina. En los años 20, Bosch participó de la fundación de la Logia San Martín, e incluso se contó entre los redactores de las bases constitutivas de dicha organización secreta. Pero luego se alejó de los posicionamientos sostenidos por ésta: durante la segunda presidencia de Yrigoyen, en efecto, disintió con quienes promovían el derrocamiento del viejo caudillo. Una vez producido el golpe de estado, asumió posturas opositoras a los gobiernos de Uriburu y Justo, y en enero de 1933 solicitó la baja del servicio activo para poder moverse con libertad en las actividades sediciosas.

Además de Pomar y Bosch, se contaron entre los referentes del Comando del Litoral Lucas Torres y Domingo Aguirre, quienes centraron su actuación en el noreste del país. Torres, de descendencia brasileña, había nacido en Misiones, y luego de un breve período durante el cual ofició de maestro de escuela, se dedicó a la política.

\footnotetext{
3 En 1946, en la campaña en que se promovería a Pomar para diputado nacional, se recordaría que su nombramiento como edecán le causó a él mismo una gran sorpresa; para justificar la designación, Yrigoyen "le recordó que le había agradado sobremanera su actitud cuando, como jefe de las tropas militares de la zona del Chaco, intervino de manera extraordinaria en un conflicto promovido entre patrones y obreros de Las Palmas. Su actuación justiciera de parte de los obreros explotados, agradó al Dr. Yrigoyen, quien premió de tal manera al militar compenetrado de tan altos propósitos”. Clarín, 22 de febrero de 1946.

4 En sus "Memorias", Pomar relata una conversación que a principios de 1931 mantuvo con un obrero en Paraná. Pomar contrasta allí su parecer con el de otro militar, Palacín, quien en un discurso pronunciado en presencia de trabajadores había manifestado que éstos "no necesitan de Sindicatos ni Federaciones, los que no hacen más que explotarlos y convertirlos en instrumentos de unos cuantos vividores extranjeros". Pomar se encontró luego con uno de los obreros que había asistido al discurso de Palacín; cuenta Pomar: "Díjele que no aprobaba los procedimientos, ni menos compartía la manera de pensar del camarada Palacín, que creía, en cambio, que los obreros tenían el derecho y hasta la obligación de agremiarse para defender, con una eficacia de que carecen aislados y desunidos, las conquistas ya alcanzadas y obtener otras nuevas. Le signifiqué que no todos los militares veíamos en los obreros sindicados y en sus instituciones representativas a presuntos enemigos del orden social democrático y de la Patria, sino que éramos muchos los que respetábamos y mirábamos con simpatía a los hombres que, con su esfuerzo honrado, ganaban penosamente el sustento de los suyos, contribuyendo, en medida mayor que ningunos, al engrandecimiento nacional; que defendíamos la Patria, pero dentro de los conceptos democráticos que constituían la tradición argentina, y que aspirábamos al afianzamiento de las instituciones, promoviendo el bienestar general por la extensión progresiva de las normas de justicia social". Gregorio Pomar, Memorias, Tomo II, versión mecanografiada inédita, 1933, pp. 134-135.
} 
Adhirió tempranamente al radicalismo, y las contiendas entre las distintas facciones de la región hicieron que en los años 20 permaneciera exilado en Brasil. Allí tomó parte en las disputas internas del estado riograndense, a raíz de las cuales entabló vínculos con políticos de esa zona -vínculos que después resultarían clave para los alzamientos llevados a cabo por el Comando del Litoral-. Según distintos testimonios, Torres contaba con un gran ascendente entre los misioneros; el carisma y la lealtad personal que sus coterráneos guardaban hacia él, antes que sus virtudes guerreras, explican el predominio que adquirió en la Zona Norte del Comando del Litoral. ${ }^{5}$

La trayectoria de su par Domingo Aguirre también reviste cierta peculiaridad. Luego de participar de la intentona liderada por Pomar en julio de 1931, Aguirre se refugió en Paraguay. Estaba exiliado en el vecino país cuando se desencadenó la guerra del Chaco; decidió tomar parte en ella, combatiendo para el bando paraguayo. Obtuvo en la contienda el grado militar de "Mayor" del ejército guaraní. A principios de 1933 regresó a la Argentina para sumarse a la Columna Norte del Comando del Litoral, la cual por ese entonces estaba siendo organizada por Torres.

Otros militares que tuvieron participación en el Comando del Litoral, aunque de menor relevancia, fueron los tenientes coroneles Francisco Bosch (hermano de R. Bosch), Sabino Adalid y Juan F. Palacios. Estos militares reivindicaron una posición más netamente "profesionalista", buscando alejar al movimiento de los partidos políticos y de la colaboración civil. En rigor, y según todo lo indica, los uniformados mencionados, por cuestiones internas del ejército, estaban enfrentados al liderazgo de Justo, y se sumaban a muchas de las distintas conspiraciones en su contra que surgían al interior de la corporación militar.

Además del ya mencionado Lucas Torres, hubo también otros civiles que desempeñaron funciones destacadas al interior del Comando. Entre ellos se encontraron, en primer término, los hermanos Mario, Roberto y Eduardo Kennedy, estancieros entrerrianos que protagonizaron un levantamiento armado en enero de 1932 en la ciudad de La Paz, a raíz del cual hubieron de refugiarse en Uruguay y compartir las sinuosidades del exilio junto con el resto de los emigrados argentinos. En segundo lugar, cabe hacer referencia a José Benjamín Ábalos, médico rosarino de larguísima trayectoria universitaria y política. Ábalos fue, de los dirigentes de primera línea del radicalismo, el que con mayor tesón se comprometió con la causa revolucionaria; se abocó principalmente a la organización de las fuerzas civiles en Rosario, aunque también participó en forma directa en algunas batallas.

Hacemos una aclaración antes de introducirnos en el análisis del accionar del Comando del Litoral. Contrariamente a lo que su nombre sugiere, éste no fue un grupo sólidamente unificado. La línea de continuidad del mismo puede seguirse, fundamentalmente, a través de la figura de Gregorio Pomar, quien desde el mismo

\footnotetext{
5 Jauretche definió a Torres como "un maestro de escuela, caudillo revolucionario de gran prestigio entre los misioneros, sobre todo entre los mensús" (cit. en Galasso, 1985: 286). Aclaramos que el término "mensú" designaba a los trabajadores rurales, y más específicamente, a aquellos empleados en las plantaciones yerbateras.
} 
día del golpe de Uriburu desplegó una actividad conspirativa ininterrumpida en las guarniciones del litoral del país. Roberto Bosch tuvo al principio una injerencia menor; a partir de la segunda mitad de 1932 tanto los informes policiales como los testimonios de sus pares de armas lo muestran acompañándolo a aquél con mayor regularidad, y a partir de 1933 ya ambos aparecen como inseparables. Por otra parte, los documentos elaborados por el grupo a veces llevaban el nombre de sus principales referentes, y otras veces la firma del Comando. Asimismo, sus integrantes se vieron implicados en forma directa en otras actividades conspirativas (por ejemplo, José Ábalos sería uno de los principales colaboradores de Cattáneo en su frustrado plan de 1932). Todo lo cual sugiere que el grupo no alcanzó grados de institucionalización elevados.

\section{La región litoral y las ventajas para la incursión armada}

La mayoría de las acciones planificadas por los líderes del Comando del Litoral reconocieron un esquema similar de procedimiento. A diferencia de los levantamientos que hasta el momento habían tenido lugar en el país, el epicentro de la acción no se situó en la Capital Federal, sino en el interior, más precisamente en las provincias mesopotámicas, las cuales ofrecían una serie de ventajas para la empresa sediciosa: en primer lugar, ellas constituían una franja de tierra que poseía la particular circunstancia geográfica de encontrarse separada del resto del país por un sinnúmero de ríos y esteros; los líderes del Comando pensaban que si lograban controlar ese rincón de difícil acceso, podrían contar con el tiempo suficiente -antes de que llegaran tropas federales- para formar una fuerza operativa capaz de transportarse después a otros puntos del territorio. ${ }^{6}$

El litoral, en segundo lugar, por ser una región fronteriza, permitía que, en caso de fracasar en su intento, los revolucionarios contaran con la posibilidad de una rápida retirada del país a través del río. Esa salida fue de hecho recurrentemente utilizada: cuando las intentonas fueron derrotadas, los rebeldes no dudaron en franquear el Uruguay para llegar a alguno de los países fronterizos del este, o bien cruzar el Paraná para albergarse en Paraguay. Una vez que pisaban tierra extranjera, los combatientes solicitaban asilo político -el cual les fue concedido en casi todas las oportunidades-.

En tercer término, en las provincias del litoral, los líderes del Comando contaban con numerosos simpatizantes. Como ya mencionamos, Gregorio Pomar había capitaneado allí tropas en varios destacamentos militares. En ellos, confiaba encontrar la adhesión de oficiales, y, sobre todo, sub-oficiales, que, llegado el momento decisivo, se plegarían al movimiento. En el mejor de los casos, incluso, los dirigentes del Comando del Litoral pensaban en la posibilidad de conquistar divisiones enteras del ejército sin necesidad de dar batalla. Jauretche, al recordar su participación en los acontecimientos de Paso de los Libres de diciembre de 1933, afirmaba en este sentido: "Nuestra columna esperaba contar con el apoyo de parte del regimiento de Paso de los Libres, que había de plegarse no bien se produjese nuestra entrada en la ciudad" (cit. en Galasso, 1985: 296). Coincidentemente, Miguel Ángel Villalba, quien entrevistó a muchos de los que

${ }^{6}$ Así lo afirmaba el mismo Gregorio Pomar en sus "Memorias" (1933: 175-176). En el mismo sentido se expresó Arturo Jauretche (véase su testimonio sobre el particular en: Galasso, 1985: 286-287). 
lucharon en ese mismo alzamiento de fines de 1933, sostiene que "todos estaban seguros del plegamiento del $11^{\circ}$ de Caballería y en tal modo, que Roberto Bosch en la arenga les aseveró que sería 'un paseo'. 'Vamos a tomar la ciudad con cuatro gritos!' se le escuchó gritar (...) Ceferino Gauto, otro ex combatiente oyó decir a Gregorio [Pomar], en más de una oportunidad que 'esto es una preventiva nomás. No necesitamos pelearlo al ejército porque está con nosotros"” (Villalba, 2012: 74).

Pero los referentes del Comando del Litoral no pretendieron sólo atraer uniformados hacia sus filas. La colaboración civil también se consideró relevante. En este sentido, en el litoral resultó particularmente valiosa la cooperación de los hacendados, quienes contaban con recursos por demás favorables para la empresa revolucionaria. Ellos eran quienes podían aportar, en efecto, no sólo tierras para la instalación de campamentos, sino también armas para los combatientes, vehículos para el traslado de hombres y provisiones, $\mathrm{y}$, posteriormente, en caso de que la acción sediciosa fracasara, trabajo para emplear a los complotados. Adicionalmente, y en no pocas ocasiones, los propietarios de estancias proveyeron también recursos humanos para la guerra. Muchos de quienes integraron las columnas revolucionarias eran, en efecto, peones que trabajaban en la estancia de algún caudillo rural que se había sumado a la causa revolucionaria, y que llevaba, imposible saber con qué grado de consentimiento, a sus asalariados a la acción militar. ${ }^{7}$

La región litoral también ofrecía ventajas en relación con ese específico tipo de colaboración civil: en las provincias de Entre Ríos, Corrientes y Misiones existía un buen número de hacendados favorables a la causa rebelde, quienes participaron activamente en las diversas contiendas.

Igual importancia adquiría el hecho de que, allende la frontera, también había grandes propietarios de tierras dispuestos a colaborar con la gesta revolucionaria. Así, en el estado brasileño de Río Grande del Sur, limítrofe con las provincias argentinas de Corrientes y Misiones, los revolucionarios pudieron contar con la invalorable colaboración de no pocos "fazendeiros" que pusieron sus tierras a disposición de la lucha de los militares argentinos. Un informe reservado de la subprefectura de Paso de los Libres de 1935 que alertaba sobre la presencia de revolucionarios en ciudades fronterizas del Brasil, afirmaba en este sentido: "En cuanto a Pomar, se asegura que se encuentra en un establecimiento de campo próximo a Uruguayana, lo que no sería de dudar si se

\footnotetext{
7 Para el asalto a la ciudad de Santo Tomé, por ejemplo, Villalba cuenta que fue muy valorada la presencia de "Roberto Billinghurst, joven abogado propietario de la estancia 'Casualidad', [quien] organizó con facilidad su grupo de caballería, favorecido por su indudable ascendiente sobre el menchaje" (Villaba, 2012: 132). Los hermanos Kennedy, para tomar la ciudad de La Paz, por su parte, se valieron, como bien dejan saber las crónicas que reconstruyen el acontecimiento, principalmente de los peones que trabajaban en sus estancias. Por lo tanto, la participación en este último levantamiento de Roberto Chavero -quien luego sería mundialmente conocido como folklorista bajo el apodo de Atahualpa Yupanqui-, así como la de Arturo Jauretche en los acontecimientos de Paso de los Libres, no deben llevar a pensar en una numerosa participación de intelectuales y artistas en los ejércitos rebeldes. En el caso que nos ocupa, esa intervención sería la excepción; la regla estuvo dada por mecanismos más tradicionales de reclutamiento de soldados (entre los cuales, además del recién mencionado, se incluyó el de la compra de mercenarios, al cual haremos referencia más adelante).
} 
Giménez. El comando del litoral y la acción armada contra el régimen de la restauración conservadora en la primera...

tiene en cuenta el franco apoyo que han tenido siempre de los hacendados de la costa del Uruguay y Cuaréim". ${ }^{8}$ Ese apoyo se había hecho efectivo en ocasiones anteriores: fue en las estancias de José Guimaraes, Pacheco Prates y José María Rodríguez de Freitas, situadas en los alrededores de la ciudad de Uruguayana, donde aquellos instalaron los campamentos y reunieron a la tropa antes de cruzar el río para tomar por asalto la ciudad de Paso de los Libres a fines de 1933; asimismo, el ataque a Santo Tomé, simultáneo al de Paso de los Libres, se planificó desde São Borja. ${ }^{9}$ Por su parte, en la República del Uruguay, también los líderes rebeldes tuvieron apoyo logístico de grandes propietarios: así, en ocasión de producirse el intento de copamiento del Batallón $1^{\circ}$ de Ferrocarrileros de Concordia en enero de 1932, se utilizó como base de operaciones la estancia de un colaborador oriental; un informe policial decía al respecto que "en un establecimiento situado cerca del Salto, llamado San Antonio, propiedad de un tal Muñoz, situado frente a la Pampa Soler, es donde reside el núcleo dirigente de Bosch, Pomar, etc.". ${ }^{10}$

Desde luego que el continuo accionar de los revolucionarios en las zonas fronterizas suscitó conflictos diplomáticos entre los países implicados. El gobierno argentino realizó constantes reclamaciones hacia sus pares de Uruguay y Brasil para que éstos se esforzaran por limitar la libertad de movimientos de los exiliados argentinos. Una nota del diario La Nación informaba al respecto:

La cancillería argentina ha iniciado una gestión cerca de la uruguaya, tendiente a que el gobierno del país vecino tome disposiciones a fin de que cesen en su territorio actividades de políticos y militares argentinos encaminadas a alterar el orden en la Argentina (...) El jefe de la cancillería nos manifestó que se había promovido una gestión diplomática por medio de la embajada en Montevideo para que se impida que en poblaciones uruguayas cercanas a la frontera, como la de Salto, se tramen actos atentatorios de la tranquilidad pública en la Argentina. ${ }^{11}$

\footnotetext{
8 Fondo Documental Justo (de ahora en adelante: $F D J$ ), Caja 100, Doc. 1, Copia de la Nota Reservada No. 9 de la Subprefectura Marítima de Paso de los Libres, 4 de abril de 1935.

9 Quien se encargara de gestionar los contactos con los hacendados brasileños parece haber sido Lucas Torres. Un estudio brasileño de historia local afirma em este sentido: "Para organizar o movimento na fronteira, os radicais da Unión Cívica, designaram os coronéis Roberto Bosch e Gregório Pomar. Mas foi um civil argentino, Lucas Torres, quem, na verdade se destacou como primeira liderança ao longo da costa, visando garantir entre os brasileiros o apoio material e humano de que necessitavam para concretizar o plano. Essa tarefa consumiu um ano de dedicação, inclusive com a realização do treinamento militar de refugiados e mercenários argentinos em fazendas da região". (Fonttes e Duarte, 2002: 146).

${ }^{10}$ FDJ, Caja 98, Doc. 122, “Asunto Donovan”, 1933.

${ }^{11}$ La Nación, 6 de julio de 1932, pág. 1. La misma cuestión suscitó un acalorado debate al interior del parlamento uruguayo: mientras desde el batllismo se mostraron receptivos a las demandas del gobierno argentino, los partidarios de Luis Alberto Herrera asumieron la defensa de los exilados. Ver La Nación, 9 y 10 de julio de 1932 .
} 
Pese a la insistencia de las autoridades argentinas, los revolucionarios siguieron contando con gran libertad de movimientos en los países vecinos. Sin embargo, y más allá de ello, resultaba evidente que era sólo consiguiendo apoyos en Argentina que se podría alcanzar el objetivo de deponer a las autoridades posrevolucionarias. En tal sentido, desde el Comando del Litoral se realizaron sendos esfuerzos por lograr la colaboración activa, sobre todo, del personal militar.

Para lograr la adhesión de los oficiales y sub-oficiales de los destacamentos militares del litoral del país, los referentes del Comando del Litoral apostaron ante todo al conocimiento y la lealtad personal que éstos podían guardar hacia algunos de sus antiguos jefes (Pomar en primer término). Pero también recurrieron a otros recursos que les permitieran acrecentar el número de uniformados comprometidos. Una intensa actividad de persuasión y propaganda fue desarrollada en ese sentido en distintos regimientos. Y aunque el contacto personal fue el medio privilegiado para sumar adeptos a la acción contestataria (los informantes de inteligencia solían por ello seguir con particular atención a quienes estaban sospechados de tramar conspiraciones), también desde el Comando del Litoral se acudió a la propaganda impresa para azuzar el descontento de la oficialidad.

Dicha propaganda se difundía a través de la distribución de folletos en las guarniciones que pretendían ganar para su causa. Dirigidos prioritariamente a lograr el consentimiento de los sub-oficiales del ejército, los panfletos solían combinar una denuncia de las políticas antidemocráticas implementadas por los gobiernos de Uriburu y Justo, con la promoción de oportunidades de ascensos para los militares que se plegaran al movimiento. Asimismo, otorgaban gran relevancia al papel desempeñado por el ejército, insistiendo en el hecho de que con la intervención directa de la corporación armada en la política se afectaba el normal funcionamiento de las instituciones de la república, al tiempo que se corroía internamente la moral castrense. De tal modo, a los oficiales y sub-oficiales se los convocaba a formar parte de una empresa destinada tanto a salvaguardar la institucionalidad democrática como a limpiar la "mancha" que la revolución de septiembre había dejado en las Fuerzas Armadas. Paralelamente, y en tanto la depuración de la entidad militar dejaría vacantes a cubrir en los grados superiores, se ofrecía a la oficialidad incentivos materiales bien concretos para tornar más tentadora la invitación de formar parte de la iniciativa rebelde. Uno de esos folletos, que fue distribuido en los destacamentos correntinos antes del alzamiento de diciembre de 1933, afirmaba en esa dirección:

El comando del Litoral, en uso de las facultades conferidas por el comando supremo revolucionario,

y teniendo en cuenta:

Que el país se encuentra gobernado por una minoría adueñada de todas las representaciones públicas, a raíz de los comicios ilegales y fraudulentos del 8 de Noviembre de 1931 .

Que, como la única manera de conservar el poder, usurpado a la soberanía popular, dicha minoría trata de provocar una reac- 
ción antidemocrática, derogando la Ley Sáenz Peña y quebrando la tradición institucional de la República, al amparo de doctrinas exóticas que sistematizan el despotismo y la violencia. Que esta situación ha podido llegar a establecerse sólo por la postura antidemocrática en que se ha colocado un determinado número de Jefes y Oficiales del Ejército, apoyando o tolerando la dictadura primero y la usurpación después, en abierta contradicción con las normas más elementales del honor militar y los deberes que comporta la ciudadanía.

Que, paralelamente a la restitución de las libertades públicas y el regreso al normal funcionamiento de las instituciones republicanas, es necesario asegurar el afianzamiento de la moral en el Ejército, que debe ser fiel y permanente custodia de las mismas; siendo por otra parte indispensable atender a la reorganización de la institución armada, eliminando a los militares indignos, por lo que habrá que proveer vacantes en los grados subalternos y de Oficiales.

Resuelve:

$\left.1^{\circ}\right)$.- Todo suboficial -Sargento Ayudante, Sargento primero y Sargento- que tenga diez o más años de servicios en el Ejército, y cuyos conceptos no afecten su moral, serán ascendidos automáticamente y reconocidos como Sub-tenientes y los Cabos primeros y Cabos, ascendidos al grado inmediato superior, en el acto del pronunciamiento revolucionario, siempre que se pongan al servicio de la causa de la libertad.- (...)

$3^{\circ}$ ).- Se considerarán comprendidos en los beneficios del artículo primero, los suboficiales destituidos, dados de baja o perjudicados en cualquier sentido, después del 6 de Septiembre de 1930, por haber intervenido en los movimientos liberadores de Corrientes del 20 de Julio de 1931, de Concordia del 2 de Enero de 1932 y en las conspiraciones de Jujuy, Córdoba, Capital Federal, Rosario y demás puntos de la República, realizadas con el propósito de derrocar la dictadura o los gobiernos de usurpación, y siempre que actúen en la preparación y ejecución de la acción decisiva.-

$4^{\circ}$ ).- Todo suboficial que sea dado de baja o sufra castigo, en lo sucesivo, por participación en la conspiración revolucionaria, será comprendido en el artículo tercero de esta resolución.-

$5^{\circ}$ ).- Comuníquese por los delegados del Comando, ejecútese y archívese por secretaría General.-

Melo, Junio de 1933.-

Tte. Coronel POMAR, Jefe Estado Mayor / Fdo. Ten1 R. Bosch, Comandante en Jefe. ${ }^{12}$

${ }^{12}$ FDJ, Caja 98, Doc. 35, Proclama revolucionaria del Comando del Litoral, Junio de 1933. 
Como vemos, los líderes del Comando del Litoral apostaban prioritariamente a obtener el aval de quienes ostentaban los grados más bajos del ejército argentino. Dicha política era consecuente con la situación imperante en el ejército: luego del golpe de septiembre, en efecto, la enorme mayoría de los oficiales opositores a Uriburu y Justo fueron pasados a retiro o dados de baja, mientras que las promociones a los grados superiores alcanzaron a quienes se mostraron leales hacia las nuevas autoridades. Resulta entonces comprensible que quienes buscaban derrocar el nuevo orden decidieran apelar a los sub-oficiales, a quienes podían convocar con una propuesta de reforma estructural de la organización del ejército.

Empero, no sólo se convocó a los oficiales y sub-oficiales a participar de la empresa sediciosa. En ocasiones, también el acompañamiento de la sociedad civil se consideró relevante. ¿Hasta qué punto avanzaron los referentes del Comando del Litoral en la articulación de estrategias con sectores sociales organizados, como, por ejemplo, los partidos de oposición y el movimiento obrero? Sobre este punto resulta imposible realizar generalizaciones válidas para todos los ensayos de revueltas ejecutados por el Comando. Todo indica, en efecto, que la índole y el alcance de la colaboración civil variaron en función de las diferentes coyunturas. En los próximos apartados nos abocaremos a la tarea de reconstruir los diferentes alzamientos protagonizados por el Comando del Litoral, describiendo la dinámica de los mismos, y preguntándonos por las apoyaturas que consiguieron en el ejército y la sociedad.

\section{Los alzamientos armados protagonizados por el Comando del Litoral: la revolución en Corrientes de julio de 1931}

En cuatro oportunidades los litoraleños pasaron de la planificación a los hechos, enfrentando con las armas en la mano a las fuerzas gubernamentales. La primera de las intentonas armadas, ocurrida en Corrientes y Chaco en julio de 1931, llegó a contar en sus inicios con ramificaciones en todo el país, y a involucrar a una gran cantidad de oficiales de diversa graduación y de distintas tendencias políticas. ${ }^{13}$ El hecho de tener lugar en un momento de extrema debilidad para el gobierno de Uriburu ${ }^{14}$ seguramente influyó para que un buen número de uniformados se plegaran al movimiento sedicioso.

En principio, se había planificado su estallido para el mes de junio. Pero diversos entredichos entre los líderes rebeldes motivaron la postergación de la ejecución. Finalmente, en las primeras semanas de julio, la mayoría de los militares implicados en la revuelta fue cambiada de destino, puesta en disponibilidad o pasada a retiro. Resultó evidente que se habían filtrado los planes y los nombres de los complotados, y que desde el gobierno y los altos mandos del ejército se estaba actuando preventivamente

\footnotetext{
${ }^{13}$ Una nómina de los militares implicados y de los regimientos comprometidos puede encontrarse en Ezcurra y Ezcurra, 1998: 24-27. Las crónicas escritas por Atilio Cattáneo (1939 y 1959), por su parte, dan cuenta del dificilísimo proceso de gestación y ejecución del movimiento. En ellas, y en las ya citadas memorias de Pomar, así como en las informaciones publicadas por los diarios de la época, nos basamos para reconstruir los acontecimientos de julio de 1931 que evocamos en la presente sección.

${ }^{14}$ Una exhaustiva crónica del proceso político luego de la revolución de septiembre se encuentra en: Potash, 1986: 88-114.
} 
Giménez. El comando del litoral y la acción armada contra el régimen de la restauración conservadora en la primera...

para desarticular el movimiento. La intentona pareció entonces terminada antes de que tuviera ocasión de ponerse en práctica. Pero Gregorio Pomar -que en el plan inicial sería el encargado de sublevar la región litoral del país, en un movimiento que se concebía como nacional- decidió de todos modos pasar a la acción. Su parecer fue que la dictadura no cumpliría la promesa de delegar el control del gobierno en comicios limpios y transparentes, y que, consecuentemente, el retorno a la normalidad sólo podría conseguirse derrocando por la fuerza a Uriburu y traspasando luego el poder a los integrantes de la Corte Suprema. Además, Pomar creía que existía un clima de rebelión latente hacia la dictadura, el cual tornaría posible contrarrestar el mayor poder de fuego de las fuerzas leales. Consecuente con ello, el 20 de julio decidió pasar a la acción.

Bien mirada, la revolución de julio de 1931 fue la más exitosa de las intentonas ensayadas. Pomar logró, en efecto, que el Regimiento 9 de infantería, situado en la ciudad de Corrientes, se plegara al movimiento sin necesidad de combatirlo directamente. ${ }^{15}$ Con ese respaldo militar, se dirigió hacia la gobernación y depuso al interventor de la provincia. Alcanzado ese primer objetivo, ordenó que un contingente del Regimiento 9 marchara a Resistencia y obligara al gobernador a delegar el poder en el Mayor Álvarez Pereyra; el cometido se cumplió rápidamente, obteniéndose así la ocupación del territorio del Chaco. En numerosas ciudades del interior de Corrientes y Chaco, paralelamente, los civiles organizados se movilizaron y derrocaron a las autoridades municipales. ${ }^{16}$

A una escala pequeña, el "modelo" revolucionario planeado resultó ser efectivo: un sector del ejército, reconociendo el liderazgo de Pomar, se acopló al movimiento, mientras en diversas localidades en las que no había presencia miliar, grupos de civiles -en su mayoría afines al radicalismo- ${ }^{17}$ aseguraron que cundiera la chispa de la revolución.

${ }^{15}$ En la ocasión, sólo resistió el jefe del regimiento, el teniente coronel Lino Montiel, quien fue ejecutado en el acto por Pomar.

${ }^{16}$ En Corrientes, fueron depuestas las autoridades de Empedrado, Ituzaingó, General Paz, San Roque, Mantilla, Saladas y Mercedes. En el Chaco, además de Resistencia, se plegaron al movimiento las localidades de Barranqueras y Presidencia Roque Sáenz Peña. Sobre las repercusiones que en Chaco tuvieron estos acontecimientos, véase: Silvia Castelán de Fracchia, 1999.

17 Sobre la participación de civiles identificados con el radicalismo resulta relevante citar la crónica del coronel Costa, quien sostuvo que era "falsa" la afirmación "de Pomar, de que el movimiento no tenía carácter político. Si bien la base eran algunas unidades del Ejército, éstas debían ser reforzadas de inmediato por elementos civiles de filiación radical personalista (...) Es tan evidente esta última afirmación, que allí donde pudieron dar expansión a sus sentimientos políticos lo hicieron gritando: viva el partido radical y viva Hipólito Yrigoyen" (cit. en Orona, 1966: 156). Es sabido que Uriburu, en igual sentido que Costa, también interpretó el alzamiento de Corrientes como una acción planificada y ejecutada por el partido radical, con lo cual justificó tanto la represión a gran escala que sobre éste aplicó, como su decisión de no permitir que referentes de dicha fracción política compitieran en las elecciones presidenciales que se celebrarían en noviembre de ese año. En contrapartida, los principales referentes y los órganos de conducción de la UCR se desligaron desde un primer momento de cualquier vínculo con los líderes rebeldes. Ello fue completamente en vano: en efecto, ante la evidencia ineludible de que militantes radicales tuvieron algún tipo de participación en la revuelta, y ante el sinfín de intervenciones que señalaban a la UCR como responsable de llevar a cabo la iniciativa armada, resultó inocua la tentativa de despegarse de éstas realizada por los principales dirigentes del partido, quienes debieron soportar el 
Pero aunque resultase inocultable que militantes y dirigentes de la UCR de las dos provincias implicadas acompañaron el levantamiento, garantizando de ese modo que no quedara confinado a la ciudad de Corrientes, desde la conducción del motín se procuró dejar bien establecido que el objetivo del mismo no tenía móviles partidarios, sino que representaba una demanda que abarcaba al conjunto de la ciudadanía. La proclama del movimiento, firmada por Pomar, en efecto, no mencionaba a ningún partido político, y descartaba de plano un eventual regreso de Yrigoyen a la presidencia, insistiendo en que lo que el movimiento buscaba era la delegación del control del gobierno en el presidente de la Corte Suprema. ${ }^{18}$ De tal modo, se pretendía desligar al alzamiento de cualquier tipo de motivación "facciosa", atrayendo para la causa a todos aquellos que no compartieran los objetivos de la revolución de septiembre.

Sucede que para que el movimiento representase un desafío serio al gobierno provisional se necesitaba tanto que nuevas guarniciones se declararan en rebeldía como que en ciudades de otras provincias se replicara la protesta registrada en algunos distritos del interior de Chaco y Corrientes. Pero ello no sucedió. En el ejército, las medidas tomadas con antelación, y la intensa vigilancia a la que fue sometida la oficialidad, probaron ser efectivas: aunque en ese momento existía un número importante de oficiales dispuestos a sumarse a la empresa revolucionaria, éstos no pudieron coordinar sus acciones con los regimientos levantados en el litoral, permaneciendo los rebeldes aislados de eventuales apoyos que pudieran conseguir en otras regiones del país. ${ }^{19}$

En lo que respecta a la actitud asumida por los civiles, la noticia de la rebelión, fuera de las localidades de Corrientes y Chaco que ya mencionamos, fue recibida con pasividad. En rigor, era difícil pensar en un levantamiento espontáneo de las masas. Y la posibilidad de contar con un vasto y orgánico apoyo por parte de la principal fuerza política de oposición, el radicalismo, resultaba muy remota, entre otros motivos porque la UCR carecía en ese momento de una estructura unificada que pudiera responder en forma cohesionada a una iniciativa de esa naturaleza (Giménez, 2014: 47-73). Por otra parte, el resultado de las elecciones de abril en la provincia de Buenos Aires, en las que el radicalismo derrotó en forma contundente a los conservadores abriendo con ello la posibilidad de un pronto retorno al poder a través del voto, había volcado al grueso del personal radical hacia la alternativa electoral, y se esperaba con grandes expectativas

peso de la represión y sufrir el veto a sus candidaturas en las elecciones de noviembre.

${ }^{18}$ Los cuatros puntos de la proclama, que llevaba la firma de Pomar, establecían: " $1{ }^{\circ}$.- Retorno inmediato a la normalidad constitucional, con la inmediata asunción del mando gubernamental de la República por el Exmo. Señor Presidente de la Corte Suprema de Justicia de la Nación, Dr. José Figueroa Alcorta. $2^{\circ}$.Constitución de gobiernos provisorios civiles en todas las provincias de la República, sin distinción de colores o credos políticos. $3^{\circ}$.- Convocatoria a elecciones simultáneas y generales para la constitución de todos los poderes nacionales, provinciales y municipales de la República. $4^{\circ}$.- Retorno inmediato del Ejército a las actividades propias de su cometido" (cit. en Ezcurra y Ezcurra, 1998: 36-37).

${ }^{19}$ Afirma Cattáneo al respecto: "El movimiento fracasó porque no fue secundado en ninguna parte. El llamamiento de Pomar fue desoído. Resultó un esfuerzo esporádico (...) El movimiento desconcertó, por más que todos tenían conocimiento de que estallaría de un momento a otro. La orden de postergación dada por el Comando Superior; el pase de oficiales, etc., había desorientado grandemente a los comprometidos, los que no pudieron cooperar en la acción iniciada en Corrientes" (Cattáneo, 1939: 88) 
Giménez. El comando del litoral y la acción armada contra el régimen de la restauración conservadora en la primera...

una próxima convocatoria a comicios para elegir representantes en la nación y las provincias. El estallido revolucionario tomó a muchos por sorpresa, y cundió fuertemente la duda sobre la conveniencia del momento elegido para emprender una acción de esas características. Adicionalmente, quien por entonces intentaba reconstruir internamente a la UCR, Marcelo T. de Alvear, apostaba a una revitalización de la organización partidaria del radicalismo. Nada más contraproducente para lograr ese objetivo que el estallido de un movimiento armado, el cual no sólo daba a las autoridades dictatoriales las excusas que buscaban para reprimir a los militantes radicales, desarticulando así los incipientes avances logrados en el proceso de reorganización, sino que también volvía a situar a la UCR en el lugar de movimiento anárquico e inorgánico del que él lo buscaba desplazar. ${ }^{20}$

En definitiva, sin poder proyectarse a otros puntos del país, y sin el acompañamiento de la ciudadanía, los revolucionarios de Corrientes debieron ceder ante las amenazas de una fuerte represión lanzadas por el gobierno nacional, y el 22 de julio abandonaron las trincheras conquistadas y huyeron hacia Paraguay, donde solicitaron el asilo político.

\section{Enero de 1932 y de 1933: La Paz y Concordia}

Muchos de los complotados se quedarían de por vida en el vecino país. Gregorio Pomar, por su parte, se dirigió hacia Uruguay, donde nuevamente comenzó a planificar una revuelta contra el gobierno de Uriburu. En la república oriental se encontró con Benjamín Ábalos y Roberto Bosch, y probablemente fue en el trascurso de esos meses que el Comando del Litoral se conformó como tal. Según distintos testimonios, la idea en un principio consistió en organizar un levantamiento que coincidiera con las elecciones del 8 de noviembre. ${ }^{21}$ Las dificultades en los preparativos motivaron la postergación del motín. En los primeros días de enero, finalmente, tuvo lugar un conato revolucionario de trascendencia estrictamente local: lo que debería haber sido un levantamiento

\footnotetext{
${ }^{20}$ En el Fondo Documental Justo se halla una carta que Alvear envió a Severo Toranzo (fechada en Río de Janeiro el 8 de septiembre de 1931). En ella, presumiblemente en respuesta a un pedido que éste le realizara para que desde el exilio aquél asumiera puestos de dirección en un próximo movimiento revolucionario, Alvear, además de no aceptar dicha solicitud, cuestionaba al alzamiento de Corrientes, del cual decía haber permanecido voluntariamente al margen: "La acción revolucionaria iniciada hasta ahora, no ha tenido ni la cohesión ni la amplitud que pudieran asegurar un fácil triunfo, evitando así que el país sufriera los desastrosos efectos de una guerra civil. Cuando estaba en Buenos Aires, dirigiendo la reorganización partidaria con tan buenos auspicios, aun cuando se me habló indirectamente de una acción revolucionaria, nunca tuve contacto directo ni una información completa de los elementos con que pudiera contarse, razón por la cual entendí y así lo manifesté que era prematuro y que nadie podría solidarizarse en esas condiciones. Ahora, ausente y lejos de la Patria, la situación es aun más difícil para mí, pues no podría prestar mi nombre para la supuesta dirección de un movimiento del que sólo tengo detalles fragmentarios y actuando en él dirigentes que proceden por cuenta propia y sin objetivos bien definidos. No basta poder hacer una revolución, es necesario tener la seguridad de cuáles serán sus consecuencias y en qué manos caerá la dirección del país después del triunfo. Se sabe siempre contra quién se hacen los movimientos revolucionarios, pero pocas veces a favor de quién”. FDJ, Caja 27, Doc. 8.

${ }^{21}$ FDJ, Caja 97, Doc. 28, “Los sucesos revolucionarios de Entre Ríos”, enero de 1932, pp. 3-4.
} 
generalizado de todo el litoral (y, por efecto contagio, del entero país), terminó, en efecto, en un tumulto limitado a la ciudad de La Paz. Los hermanos Mario, Roberto y Eduardo Kennedy fueron los protagonistas exclusivos de los hechos.

Estancieros de profesión, y pertenecientes a distintas fracciones del radicalismo local -mientras el último militaba en el personalismo, los otros dos eran conocidos referentes del antipersonalismo entrerriano-, luego de la revolución de septiembre los tres hermanos decidieron dejar a un lado las disidencias, unificar sus posturas, y poner sus hombres y armas a disposición de la lucha contra la dictadura. En los últimos meses de 1931 entraron en contacto con Pomar y otros militares rebeldes, con quienes se encontraron en sucesivas oportunidades en la ciudad uruguaya de Salto. Los uniformados los instruyeron para actuar en coordinación con otros estallidos que se producirían en el litoral. Según el testimonio de Mario Kennedy, ellos recibieron "las indicaciones del comando revolucionario para que no lleváramos a cabo ninguna acción en el mes de diciembre (...) nuestra acción debía coincidir exactamente con los levantamientos que se iban a cumplir en Goya, en Curuzú Cuatiá y principalmente en Concordia" (cit. en Cesario, 2004: 13).

No tenemos conocimiento acerca de cómo se pensaba inducir el levantamiento en otras ciudades del litoral. Sí sabemos que en Concordia, considerada el foco principal de la revuelta, la idea era atacar los regimientos militares con asiento en la ciudad. El núcleo dirigente del Comando cruzaría el mismo día del levantamiento el río Uruguay, desde Salto hacia Concordia. Allí lo esperaría un contingente de uniformados y civiles, con quienes marcharían a las inmediaciones del centro de la ciudad, donde se encontraban los destacamentos que se pensaba tomar por asalto. Sin embargo, la incursión terminó en un fracaso absoluto. El informe anónimo titulado "Los sucesos revolucionarios de Entre Ríos" se refería a lo acontecido en Concordia en los siguientes términos:

Sólo trece argentinos pasamos el Uruguay aquella noche: el Dr. Abalos, el teniente coronel Pomar, el comandante Ignacio D. López, el teniente de los Ríos, los sargentos primeros Velázquez y González, los ciudadanos civiles Héctor Varela, Dr. Pablo Rueda, Segundo Morales, H. Morris, Miguel Ángel Durruty y T. Monticelli, y el que suscribe.

Inmediatamente de pisar el suelo patrio nos dirigimos todos juntos a la casa habitación del señor Soler Urquiza, situada a unos cuatro kilómetros más o menos de la costa en dirección a Concordia. Los hermanos Soler se habían comprometido desde muchos meses atrás a tener listos 400 ciudadanos en la extensa propiedad de la familia en la costa del uruguay, para apoyar nuestro movimiento en el momento de su realización. Fuimos, pués, grandemente sorprendidos cuando al llegar a la casa de campo arriba mencionada sólo encontramos dos suboficiales del 6 de Caballería y tres de Ferrocarrileros, además de 
veinte ciudadanos civiles, muchos de los cuales no conocían el manejo del máuser.

La ausencia del oficial que debía esperarme en la costa con 30 hombres de su regimiento, la de la inmensa mayoría de los civiles y la noticia que se nos trasmitía, de que los regimientos de la guarnición habían sido despertados y hechos formar a las 10 de la noche (amén de la concentración de las fuerzas policiales y de las que responden a la subprefectura de Concordia) nos hicieron reflexionar respecto de la oportunidad de proseguir el movimiento. ${ }^{22}$

Según narraba a continuación el autor del suelto, un grupo de hombres intentó acercarse al regimiento de caballería, pero de inmediato fueron divisados y perseguidos, motivo por el cual emprendieron la retirada, cruzando nuevamente el río hacia Salto.

Mientras en Concordia, por lo tanto, la rebelión no pasó de ser una tentativa infructuosa, en el resto de las ciudades del litoral persistió la más absoluta calma. Sólo en La Paz, seguramente como consecuencia del desconocimiento de que nada había pasado en otros puntos del país, se activó el núcleo revolucionario. Tal como estaba previsto, en la madrugada del día 3 de enero, los hermanos Kennedy, junto con un grupo de 60 hombres, tomaron la jefatura de la policía local. La asonada sólo podía encontrar su sentido si recibía acompañamiento en otros puntos del país. Pero, aislada y sin apoyos, sus horas estaban contadas. Al mediodía del mismo 3 de enero, resultó evidente para los revolucionarios que la esperada huelga general no se había producido, y que el resto de las localidades del litoral permanecían en tranquilidad. Sin más alternativa que huir, los rebeldes abandonaron la ciudad y emprendieron una fuga que alcanzó ribetes espectaculares -y que ha sido narrada en numerosos relatos literarios-..$^{23}$

Por su parte, el núcleo dirigente del Comando del Litoral, al regresar a Uruguay, fue perseguido por las autoridades orientales. Pomar y el resto de la tropa huyeron hacia el Brasil, y allí se ordenó su internación en Porto Alegre, donde permanecieron desde febrero de 1932 hasta mayo del mismo año. Una vez finalizado su confinamiento, retornaron a Uruguay. Se asentaron en Montevideo, realizando periódicas incursiones a la zona fronteriza. En la segunda mitad de 1932 los litoraleños participaron, aunque desempeñando funciones secundarias, en el plan sedicioso elaborado por Atilio Cattáneo.

\footnotetext{
${ }^{22}$ FDJ, Caja 97, Doc. 28, "Los sucesos revolucionarios de Entre Ríos", enero de 1932, pp. 3-4.

${ }^{23}$ Luego de dejar la comisaría, los hermanos Kennedy se internaron en las tierras de su propiedad; un grupo de policías y militares los persiguió hasta allí sin éxito (seis personas de dicho grupo murieron como consecuencia de los enfrentamientos). A sabiendas de que resultaba suicida intentar capturar a los Kennedy en los montes que éstos conocían tan bien, el gobierno decidió atacarlos por aire: envió cinco aviones que sobrevolaron la zona y descargaron sobre los bosques barriles de combustible. Un incendio de grandes dimensiones cubrió la zona; los Kennedy, sin embargo, lograron escapar, llegaron hasta Sauce (Corrientes), donde cruzaron el río a nado y se internaron en Uruguay. El primero en darle forma literaria a estos hechos fue el poeta uruguayo Yamandú Rodríguez (1934). Más recientemente el tema ha sido revisitado por D. Gonzalez Rebolledo (2005) y R. Lopa (2008).
} 
Abortado éste antes de que pudiera ponerse en práctica, desde el Comando del Litoral se decidió de todos modos llevar a cabo una tentativa armada.

En enero de 1933 se emprendió una acción muy similar a la promovida un año atrás: nuevamente el Comando del Litoral decidió tomar por asalto los regimientos de la ciudad de Concordia. En esta ocasión, la incursión se centró en el Batallón de Ferrocarrileros 1 con asiento en la localidad. Un grupo de 15 personas, lideradas por Pomar y Bosch, irrumpieron el 7 de enero a la medianoche en dicho destacamento, despertaron a los soldados y les ordenaron formar. Pero no sólo no lograron que la tropa les respondiera, sino que los oficiales a cargo del regimiento resistieron, generándose una balacera que dejaría un saldo de tres muertos (todos pertenecientes a las fuerzas leales). Los rebeldes emprendieron la retirada, cruzando a nado el río Uruguay. Del otro lado de la frontera los esperaba la policía, que había sido oportunamente alertada por las autoridades argentinas. ${ }^{24} \mathrm{El}$ gobierno uruguayo dispuso de inmediato la internación de los complotados en la ciudad de Melo, donde permanecieron por un período de siete meses.

Resulta difícil comprender los motivos por los cuales los revolucionarios litoraleños emprendieron una acción tan arriesgada. Todo indica que un diagnóstico muy ingenuo los llevaba a pensar que bastaba encender cualquier núcleo revolucionario para que el país se alzara en armas y el gobierno cayera. Un informe sobre los acontecimientos elaborado por la policía concordiense, decía en este sentido: "Algunos exilados han hecho manifestaciones confidenciales a ciertas autoridades del Salto (R.O.) de que ellos están seguros de que el próximo golpe, no les fracasará siempre que en cualquier punto de la República se sostuvieran 12 horas, pués contarían en ese caso con el apoyo de gran parte del Ejército, dicen contar asimismo con igual proporción en la Marina y diez (10) aeroplanos". ${ }^{25}$ En idéntica dirección, otro informe de la misma delegación, elaborado tiempo después pero que expresa una similar postura, hacía referencia a

${ }^{24}$ Un diario concordiense informaba: "Una vez fracasado el movimiento, los complotados emprendieron la huida en dos de los automóviles que los aguardaban detrás del campamento del batallón 1 de ferrocarrileros (...) La fuga de los asaltantes ha sido evidentemente precipitada, y es innegable que una suerte excesiva los ha acompañado en su criminal aventura. Para repasar el río, como en general no deben ser buenos nadadores, se valieron de los más extraños medios. En efecto, los prófugos arrancaron la puerta de un rancho abandonado y con ella hicieron una especie de balsa, que ocuparon dos o tres sujetos, otro se valió de una cámara de un automóvil para mantenerse a flote y hubo quien lo hizo en un tronco de árbol, y así, dejándose arrastrar a la deriva por las aguas, fueron a dar frente mismo al saladero de La Caballada, siendo apresados por las fuerzas de guarnición en Salto, cuyo comando las había apostado a lo largo del río, entre este paraje y la usina de las aguas corrientes, al enterarse de lo que ocurría en Concordia (...) Los fugitivos de Concordia que cruzaron el río en la forma que hemos relatado, y que las fuerzas del ejército uruguayo apresaron al llegar a la otra orilla, son los tenientes coroneles Gregorio Pomar y Roberto Bosch, el teniente Mario Lisboa, y los señores Mario Kennedy, Ramón Sáenz, Tomás Zumalacarregui, Juan Fonseca y Carlos Pilzzul. Todos ellos fueron llevados enseguida a la jefatura de policía de la vecina ciudad, donde han permanecido detenidos hasta esta mañana a las 8.15 (hora uruguaya), en que salieron para Estación Sayago, cerca de Montevideo, donde cambiarán de tren para llegar a la localidad de Melo, en el departamento de Cerro Largo, fronterizo con el Brasil". El Litoral, Concordia, 9 de enero de 1933.

${ }^{25}$ FDJ, Caja 98, Doc. 1, "Datos recogidos en el día de hoy (9 de enero de 1933) en la vecina ciudad del Salto por el suscrito -el comisario de órdenes de Concordia- y el jefe de investigaciones del mismo punto", p. 3 . 
Giménez. El comando del litoral y la acción armada contra el régimen de la restauración conservadora en la primera...

"una conversación escuchada en la otra banda a algunos 'amigos' según la cual: 'si ellos lograran dominar la situación durante seis horas en Concordia e informar como corresponde a quienes ellos sabían estaban seguros de que en todo el país triunfaría la revolución...". ${ }^{26}$

Ateniéndonos a estas afirmaciones, que se condicen bien con las acciones emprendidas por los líderes del Comando del Litoral, se puede deducir que éstos estaban convencidos de que bastaba con tomar por asalto un regimiento y lograr sostener la posición durante un breve período de tiempo para provocar la caída de las autoridades nacionales. Como se desprende también de esas declaraciones, lo fundamental para ellos era conseguir apoyo militar; una concepción puramente instrumental del poder los llevaba a pensar que para ejecutar una revolución no se necesitaba la construcción de alianzas sociales, ni la negociación de acuerdos con actores políticos, ni la maduración de un clima propicio. Tan sólo consiguiendo la movilización de tropas afines, y paralizando las leales, se podría dar por tierra con todo un régimen político. ${ }^{27}$ Retrospectivamente, esa concepción puede parecernos un desatino. Y aunque no negaremos que los grupos rebeldes nunca contaron con serias posibilidades de imponerse ni de introducir cambios en la correlación de fuerzas existente, también es necesario reponer el contexto en que actuaron quienes emprendieron la vía armada: el orden político vigente desde septiembre de 1930 nació de un alzamiento militar que había movilizado a una ínfima cantidad de tropas, y luego logró consolidarse a través de unas elecciones en las cuales se excluyó con argumentos a todas luces parciales e improcedentes al partido mayoritario. La arbitrariedad del régimen político y el fundamento de fuerza que lo sustentaba eran visibles. Resultó entonces lógico intentar derribarlo por la fuerza, consiguiendo para ello el aval de unos cuantos regimientos y militantes afines. Quizá éste sea un ejemplo

\footnotetext{
${ }^{26}$ FDJ, Caja 98, Doc. 122, “Asunto Donóvan”, 1933 (sin fecha precisa), p. 2.

${ }^{27}$ Con todo, es preciso señalar que el ataque a Concordia no fue una tentativa aislada. Aunque dispersos, el mismo día se registraron motines en localidades de Misiones, Corrientes y Buenos Aires. En el nordeste del país ya había comenzado a actuar la Columna Norte del Comando del Litoral, teniendo ocasión sus integrantes de protagonizar sus primeros levantamientos. En San Isidro (Misiones), según informaba La Nación, "fue asaltada la Prefectura Marítima por un grupo como de 20 hombres armados que pasaron del Brasil, capitaneados por Lucas Torres; ocuparon de improviso el destacamento de la marinería y apoderáronse de armas y municiones, dirigiéndose luego al interior del territorio. Regresaron rápidamente en las horas de la mañana, huyendo al Brasil" (La Nación, 9 de enero de 1933). Por otra parte, en la misma madrugada, "otro grupo de radicales personalistas atacó San Carlos (Corrientes), tomando la comisaría, Correo y oficinas públicas" (La Nación, 9 de enero de 1933). Al parecer, ambos movimientos tuvieron como objetivo primordial hacerse de armamento y municiones; si la rebelión se replicaba en otros puntos del país, debían mantener las posiciones conquistadas, asegurando que el espíritu revolucionario persistiera y se generalizara. En la provincia de Buenos Aires, por su parte, hubo motines en General Belgrano, Olavarría y Avellaneda. En las tres ciudades se intentó asaltar la comisaría local; sólo en la primera de ellas se logró el cometido, aunque por corto tiempo, dado que cuando llegaron los refuerzos policiales de las localidades vecinas, los revoltosos se dieron a la fuga. Desconocemos si existieron vínculos entre estos levantamientos y los protagonizados por el Comando del Litoral en el nordeste del país. Lo más probable es que fuesen piezas del plan de Cattáneo que reaccionaron cuando percibieron que había lugares donde coletazos de la esperada revolución se estaban poniendo en movimiento. Lo que de modo aislado sucedió en esos puntos debería haber sido la nota general en el plan originariamente trazado. Pero, al ser la excepción más que la norma, estuvieron lejos de poder surtir el efecto buscado.
} 
cabal de los efectos perniciosos que la revolución de septiembre produjo en el escenario político argentino. Al confundir las esferas civil y militar, y al introducir la fuerza como fundamento primero y último del poder, tornó omnipresente en la vida pública la dimensión de la violencia, a la cual los partidos políticos y las organizaciones de la sociedad civil comenzaron a ver cada vez como menos extraña.

\section{Diciembre de 1933: Paso de los Libres y Santo Tomé}

Las sucesivas derrotas estuvieron lejos de amedrentar a los líderes del Comando del Litoral, quienes desde Melo comenzaron a planificar la próxima incursión armada. En aquella alejada ciudad uruguaya, sin embargo, los medios de que disponían eran sumamente escasos, además de que prácticamente no tenían comunicación con el resto de los potenciales complotados. ${ }^{28}$ En consecuencia, para poder entrar nuevamente en acción, debieron esperar a que el gobierno de Uruguay levantara el confinamiento que recaía sobre ellos. En julio de 1933, finalmente, se les comunicó de forma oficial que recuperaban la libertad de movimiento por el país. Se dirigieron entonces hacia Salto, para comenzar a darle forma a lo que sería la última revolución armada llevada a cabo por el Comando del Litoral.

El de diciembre de 1933 fue, de lejos, el alzamiento más ambicioso de los tramados por los litoraleños. Por primera vez, éstos se propusieron el objetivo de formar en tierra extranjera una milicia propia que les sirviera como grupo operativo para tomar por asalto varios regimientos fronterizos de Corrientes y Misiones. La idea fue atacar simultáneamente, y desde el exterior, ambas provincias argentinas, reforzando la coordinación entre las dos "columnas" del Comando del Litoral. Paralelamente, en la zona metropolitana, Francisco Bosch se encargaría de sublevar los regimientos de caballería de Ciudadela y de tomar el control de la base aérea de El Palomar. Se esperaba además que golpes civiles en Buenos Aires, Rosario y Santa Fe acompañaran la acción militar. Ésta constituyó una novedad de importancia: a la presencia civil -tanto de militantes de partidos políticos como de organizaciones del movimiento obrerose le otorgó mucha mayor relevancia que en las ocasiones anteriores. El epicentro de la estrategia seguía siendo de todos modos, la región litoral; allí los revolucionarios esperaban vencer fácilmente a las tropas leales, ganar para la causa numerosos destacamentos militares, y dirigirse luego en tren hacia Buenos Aires, recogiendo en el camino a nuevos contingentes adictos que se irían sumando. ${ }^{29}$

Lucas Torres y Domingo Aguirre quedaron a cargo del brazo norte del Comando. Tenían como misión atacar algunas pequeñas localidades del sur de Misiones y del norte de Corrientes. El blanco más importante que se fijaron fue Santo Tomé, ciudad a la que pensaban arribar desde Sao Borja; en los alrededores de este poblado fronterizo

\footnotetext{
${ }^{28}$ Raúl Barón Biza cuenta un viaje que realizó a Melo desde Montevideo. Según relata, tardó dos días en llegar a destino. En esa ciudad, encontró a los exilados en condiciones paupérrimas. Véase su relato en: Baron Biza, 1934: 33-34.

${ }^{29}$ Sobre el plan general de la intentona de diciembre de 1933, véanse los testimonios de Jauretche y R. Bosch citados en Galasso, 1985: 283; y Villalba, 2012.
} 
Giménez. El comando del litoral y la acción armada contra el régimen de la restauración conservadora en la primera...

se asentó el campamento rebelde. De la milicia formaron parte algunos civiles, pero el principal componente del batallón estuvo dado por personal del ejército brasileño.

Más al sur, en las inmediaciones de Uruguayana, se conformó el grupo que tomaría la ciudad de Paso de los Libres. Los líderes de la "Columna Sur" del Comando fueron Gregorio Pomar y Roberto Bosch, quienes, para conformar la tropa, se valieron de elementos por demás heterogéneos: la base más numerosa estuvo dada por suboficiales del ejército argentino que habían participado en algunas de las anteriores intentonas, y que a raíz de ello resultaron dados de baja de sus funciones y cargos en las Fuerzas Armadas. También fueron de la partida militantes del radicalismo de distintos puntos del país (principalmente de Entre Ríos, Corrientes y Misiones, aunque también llegaron hasta allí correligionarios de la Capital Federal, Buenos Aires, Córdoba y Santa $\mathrm{Fe}$ ). Y por último, participaron trabajadores rurales que arribaron de la mano de alguno de los caudillos radicales de la zona. ${ }^{30}$ En total, y según los distintos testimonios, el grupo llegó a contar con casi dos centenares de "soldados" -a todos los integrantes de la milicia se les asignó el grado de "tenientes"- que recibieron durante varios meses instrucción militar.

Las autoridades argentinas tomaron conocimiento de lo que estaba aconteciendo en los campos del vecino país. Un memo policial fechado el 13 de diciembre y firmado por el Jefe de la Seccional de Paso de los Libres informaba a sus superiores en Buenos Aires:

\section{Está comprobada existencia en departamento Uruguayana (Brasil) y a inmediaciones del paso "Vado" sobre río Uruguay, frente Bompland, que los revolucionarios argentinos tienen un campo de instrucción a civiles reunidos en buen número cuya cantidad se precisó hoy en más de 200 personas, quienes operarán en momento oportuno al mando del ex Tte Coronel Pomar, atacando sobre P. Libres, secundado de otro grupo}

\footnotetext{
${ }^{30}$ Afirma Villalba: "Hay peones de estancia que son 'enganchados de prepo' y prácticamente obligados a incorporarse, otros consecuentes y convictos, como la fiel peonada de Tito Bompland y los hay quienes se ofrecen voluntarios porque son 'conocidos' de algunos cabecillas. En general, la cosecha es fruto de la campaña proselitista que en apoyo a su revolución hacen Roberto Bosch y Gregorio Pomar en todas las poblaciones de la costa Uruguay, donde su prestigio, sobre todo del último, es grande" (2012: 51). Respecto a la heterogeneidad de quienes se alistaban en la milicia, dice un testigo directo de los acontecimientos, Juan José López Alfaro, en un testimonio que reproduce Barón Biza: "Respondiendo al patriótico llamado, vimos llegar a los primeros contingentes de ciudadanos. Estos venían de las provincias de Corrientes, Entre Ríos, Santa Fé, del Territorio Nacional de Misiones y de la Capital Federal (...) Muchachos jóvenes, hombres maduros, estudiantes, profesionales, hombres de comercio, hacendados y simples ciudadanos que habían abandonado todas sus actividades, cruzaban el río trasponiendo las fronteras de la Patria, para alistarse en aquel contingente de hombres libres" (R. Baron Biza, 1934: 54-55). Arturo Jauretche, por su parte, en el poema gauchesco en que narró la gesta revolucionaria, afirma en el mismo sentido: "Vienen de todos los puntos, / porteños y provincianos; / de nuevo se encuentran juntos / para luchar, los hermanos"; y más adelante: "Son hombres muy desparejos; / hay gauchos y maturrangos, / hay muchachos y hasta viejos / que se han venido al fandango, / pobres, ricos, flacos, gordos / ignorantes y hasta sabios, / pero no hay ninguno sordo / ante los patrios agravios" (2002: 38 y 67).
} 
en campaña 'Itaquí' frente Alvear, dirigidos por Tte Coronel Bosch, secundados también por grupo que está reunido campaña departamento 'San Borja'. Sábese de fuente muy seria que cuentan con excelente elemento de combate, incluyéndose en ellos gran número de bombas de mano, llevadas desde nuestro territorio hace breves días. Además para secundar verdad de nuestra campaña se precisa en estos momentos desaparición casi totalidad caudillos rurales principalmente sector P. Libres, Bompland, San Martín, etc. ${ }^{31}$

Acorde con la información recibida, desde el gobierno se redobló la presencia de personal militar en la zona amenazada, y se ejerció presión sobre las autoridades brasileñas para que frenaran la organización en su territorio de milicias que tenían como finalidad explícita alterar el orden en la Argentina. Los reclamos fueron, en parte, atendidos. El 23 de diciembre el ejército brasileño irrumpió en uno de los campamentos rebeldes, incautó gran cantidad de armamento, y tomó prisionero a Pomar y a 150 personas más. Mientras éstas resultaron rápidamente liberadas, Pomar permaneció en prisión -fue conducido a Porto Alegre, donde se ordenó su internación-.

La ausencia de Pomar-líder indiscutido del Comando, y el único capaz de suscitar apoyos en los regimientos que se pensaba ganar para la causa-, la certidumbre de que el "factor sorpresa" había quedado anulado -puesto que era evidente que las autoridades argentinas estaban al tanto de que se pensaba realizar un movimiento sedicioso desde el Brasil-, y la sustracción de parte importante del material bélico, introdujeron serias dificultades en la puesta en marcha del movimiento. Pese a ello, Roberto Bosch decidió emprender la acción sin dilaciones: el 29 de diciembre ordenó la movilización. A la madrugada de ese día, los rebeldes, levantando la consigna "Por la soberanía popular, que es la libertad de la Patria", cruzaron el río a la altura de la localidad de Bompland, situada unos treinta kilómetros al sur de Paso de los Libres. Marchaban hacia esta ciudad cuando fueron sorprendidos por un piquete de tropas leales. Tuvo lugar allí, a la altura del arroyo San Joaquín, una batalla con saldo negativo para los revolucionarios (ocho soldados resultaron muertos, mientras la caballería quedó diezmada, y el armamento aun más menoscabado). Previendo ya que las chances de éxito eran muy escasas, un grupo de soldados encabezado por José B. Ábalos decidió abandonar la empresa y retornar al Brasil. La tropa, quebrada moralmente y disminuida numéricamente, prosiguió su rumbo hacia Paso de los Libres. Al llegar a la ciudad notaron, en palabras de López Alfaro, que "el enemigo había tomado todas las precauciones a fin de resistir el próximo ataque de nuestras fuerzas" (cit. en Baron Biza, 1934: 64). Efectivamente, los blancos que se habían fijado los revolucionarios se encontraban bien pertrechados. La única esperanza para tornar equilibrada la batalla residía en el plegamiento del 11 de Caballería, destacado en la ciudad. Éste permaneció, sin embargo, leal. En la primera trifulca, desatada en la sede del correo, los revolucionarios fueron rápidamente vencidos.

${ }^{31}$ FDJ, Caja 98, Doc. 113, Parte Telegráfico, Paso de los Libres, 13 de diciembre de 1933. 
Giménez. El comando del litoral y la acción armada contra el régimen de la restauración conservadora en la primera...

Aquellos que tuvieron la suerte de no caer muertos, emprendieron una caótica retirada hacia el Brasil. Alrededor de un tercio del batallón inicial perdió la vida en la incursión a Paso de los Libres.

El mismo día que la columna sur era derrotada, Torres y Aguirre emprendían el avance hacia Santo Tomé. Pudieron penetrar en la ciudad sin mayores inconvenientes: el ejército de que disponían, de alrededor de 150 hombres (la mayoría de ellos soldados brasileños que recibieron la promesa de una paga a cambio de participar de la contienda), alcanzaba y sobraba para quebrar la endeble defensa de esa pequeña localidad del norte de Corrientes -defensa que consistía en una delegación policial y otra de subprefectura-. Sin embargo, una vez hechos del control de la situación en Santo Tomé, se encontraron absolutamente aislados. Ninguna otra localidad del litoral acompañaba a esa altura la acción de los revolucionarios. Y en el resto del país nuevamente lo que predominaba era la calma: sólo algunos incidentes se registraron en la provincia de Santa $\mathrm{Fe},{ }^{32}$ mientras que en la Capital Federal, debido a que la policía actuó preventivamente, los motines planificados no alcanzaron a ponerse en movimiento. ${ }^{33}$

Igualmente grave resultó que los revolucionarios tampoco hallaron acompañamiento popular en aquellos lugares en los que se levantaron en armas. López Alfaro, con mucha indignación, afirmó: "La mayor parte de nuestros correligionarios de Paso de los Libres no ocuparon el lugar que las circunstancias aconsejaban. Permanecieron cobardemente cerrados en sus respectivos domicilios" (cit. en Baron Biza, 1934: 64). Lucas Torres, en igual sentido, apuntó que "exceptuando a los pocos amigos que cruzaron el río con nosotros, nadie más participó de la lucha. Esperábamos que nos llevaran una ayuda de la que mucho necesitábamos" (cit. en Villaba, 2012: 180). En el caso de Santo Tomé, es necesario además señalar que la frialdad inicial de la población respecto a la revuelta tornó en franca hostilidad cuando los mercenarios brasileños, al dar por cumplida su tarea, exigieron cobrar lo que se les había prometido, y al no ver satisfecha su demanda por parte de los jefes revolucionarios, iniciaron el pillaje a los comercios de la zona e intentaron asaltar el banco de la ciudad.

En definitiva, la revolución ejecutada por el Comando del Litoral concluyó en una cruel derrota. En el tendal quedaron casi un centenar de muertos, un número importante

\footnotetext{
${ }^{32}$ En la ciudad de Santa Fe, Rosario y Cañada de Gómez se registraron movilizaciones emprendidas por civiles, con tomas de destacamentos policiales y de bomberos; los regimientos que deberían haber secundado la iniciativa civil, sin embargo, nunca se pronunciaron, y por ello el orden pudo ser restablecido. Véase: La Nación de los días 28, 29, 30 y 31 de diciembre de 1933.

${ }^{33}$ En la capital y la zona metropolitana Francisco Bosch era el encargado de sublevar los destacamentos militares y de movilizar a los civiles. La policía, sin embargo, enterada de los planes, detuvo primero a Bosch, y luego, en los puntos de concentración establecidos para iniciar la revuelta, desató una redada en la que resultaron apresadas más de doscientas personas. Asimismo, 80 suboficiales, en teoría comprometidos con la acción sediciosa, fueron enviados a prisión. Una pormenorizada reconstrucción de lo acontecido en la Capital Federal antes y durante el 29 de diciembre de 1933 fue realizada por Juan Giordano, en: "Informe reservado con relación a los hechos del 29 de diciembre", reproducido en A. Cattáneo, 1959: 293-327. Otro testimonio que se puede consultar es el de Barón Biza (1934: 47-48), quien ese día, junto con otras ocho personas, tenía la misión de posesionarse de la base aérea de El Palomar. Ambos testimonios aseguran que una delación dio por tierra con el plan propuesto.
} 
de detenidos, y otro tanto de exiliados. Los principales referentes del Comando lograron refugiarse en el Brasil. Primero permanecieron detenidos en Porto Alegre, después fueron llevados a Río de Janeiro, y finalmente se ordenó su confinamiento en la ciudad de Bello Horizonte. Obtuvieron la libertad de movimiento en abril de 1934.

Enseguida después de su liberación, los líderes del Comando volvieron a tramar levantamientos y conspiraciones. La estrategia continuó siendo, en esencia, la misma: desde Montevideo, a través de encargados y mensajeros, intentaron fomentar el descontento entre los sub-oficiales, a quienes trataban de convencer del próximo triunfo de la rebelión. Las duras derrotas anteriores, empero, motivaron que esa incitación a la revuelta encontrara cada vez menos eco entre los uniformados. Pese a ello, los líderes del Comando no se dieron por vencidos fácilmente. Los informes de inteligencia -que a esa altura habían alcanzado una eficiencia notable, al punto de que lograban registrar todos y cada uno los movimientos realizados por los líderes rebeldes-, dan cuenta de la intensa actividad desplegada por ellos desde mediados de 1934 en adelante. ${ }^{34}$

Es imposible saber cuándo los líderes del Comando del Litoral decidieron deponer su actitud, y hasta cuándo el Comando continuó en funciones como tal. Los documentos hallados en el archivo de Agustín Justo, que inexplicablemente se interrumpen a principios de 1936, muestran todavía al grupo en plena actividad. El Comando aparece incluso a mediados de la década más consolidado como actor colectivo (sus incursiones llevan con mayor frecuencia que antes la firma "Comando del Litoral"), y también emprendiendo ambiciosos proyectos, como el desarrollo de un sistema de telecomunicaciones capaz de unir la costa del Uruguay con Montevideo y Buenos Aires. Y cuando la serie de fraudes comenzó a sembrar el descontento entre los radicales, nuevamente los revolucionarios parecen haber impulsado intentos de torcer el rumbo de los acontecimientos a través de movimientos armados. ${ }^{35}$

\footnotetext{
${ }^{34}$ Ya en junio de ese año se informaba de una reunión en Brasil en la que se habló de ejecutar una nueva revolución; un informe apuntaba: 'El día 3 en jurisdicción de 'La Estancia Vieja' a unos siete kilómetros de la estancia 'La Florida', situadas ambas entre San Borja y Uruguayana, se llevó a cabo una reunión del titulado 'Comando del Litoral'. Asistieron alrededor de 300 hombres presidiendo la reunión en calidad de jefe supremo Ruis Moreno en representación de Pomar (...) Resolvieron la preparación efectiva de un movimiento en todo el Litoral, no fijándose fecha, pero se cree para septiembre”. FDJ, Caja 99, Doc. 13, Informe del Jefe de la oficina de Correos y Telégrafos de Paso de los Libres, 5 de junio de 1934. En enero de 1935, cuando se decidía el levantamiento de la abstención en la UCR, desde el Comando se mostraron favorables a la táctica del "comicio armado" (véase: $F D J$, Caja 100, Doc. 2, Boletín de Informaciones No. 2, 2 de enero de 1935). A lo largo de toda la primera mitad de ese año, continuaron los trabajos revolucionarios. Un informe de junio decía: "El ex-Tte. Coronel Pomar ha indicado que los trabajos en Concordia deberán estar listos para dentro de 15 días (...) Significó Pomar que hay que encaminar la propaganda en el sentido de afirmar que no es un movimiento inmediato de lo que se trata sino una acción tendiente a la organización de todos los suboficiales de nuestro Ejército, los que, más adelante y ya organizados, tomarán contacto con Jefes y Oficiales en el momento que el Comando Supremo así lo determine". FDJ, Caja 100, Doc. 23, Boletín de Informaciones No. 23, 10 de junio de 1935.

${ }^{35}$ Atilio Cattáneo le informaba a Alvear a fines de 1936: "El ambiente subversivo ha comenzado a agitarse con argumentos antojadizos de toda especie, los que, desgraciadamente, toman cuerpo y producen confusión por el ambiente propicio que ha creado ese desaliento expuesto, agregado al que produce la secuela de fraudes y de artimañas que piensa utilizar el gobierno nacional en las elecciones de Santa Fe. He viajado hasta Montevideo para conversar con los amigos de allí, con el fin de paralizar las charlas
} 
Sin embargo, también es cierto que entre sus referentes se produjeron algunos conflictos de importancia. Ábalos le reprochó a Bosch su actuación durante la incursión a Paso de los Libres, ${ }^{36} \mathrm{y}$, luego de que se decidiera el retorno a las urnas de la UCR, regresó a la Argentina para presentarse como candidato a gobernador de Santa Fe en las elecciones que se celebraron en esa provincia en junio de 1935. Los hermanos Kennedy, por su parte, también cuestionaron acerbamente a sus anteriores compañeros ${ }^{37}$ cuando en 1937 regresaron a la Argentina se sumaron a las huestes del antipersonalismo, respaldando la candidatura de Ortiz a la presidencia. Roberto Bosch y Gregorio Pomar permanecieron en Uruguay hasta los primeros años de la década del cuarenta. El primero de ellos retornó al país a principios de 1941, y continuó fomentando desde aquí la prédica "revolucionaria"; para ello fundó una agrupación que recibió el nombre de Cruzada Renovadora, la cual se reconocía como de tendencia radical aunque asumió posturas claramente confrontativas hacia la conducción de Alvear. Gregorio Pomar regresó en 1942; después de pasar por un breve período de inactividad política, se involucró en la lucha partidaria, siendo elegido diputado nacional por la UCR durante la primera presidencia de Perón.

\section{Reflexiones finales}

En el presente artículo reconstruimos el derrotero seguido por el Comando del Litoral en la primera mitad de la década del treinta. Tomando como punto de anclaje los hechos de armas que el agrupamiento llevó a cabo, dilucidamos los motivos por los cuales éste decidió actuar en la región litoral, reflexionamos sobre las relaciones que el colectivo estableció con sectores civiles y militares, y arriesgamos hipótesis sobre las razones del escaso éxito de las sucesivas empresas sediciosas. Una cuestión clave que ha estado presente en las páginas anteriores, y sobre la cual nos interesa reflexionar de modo explícito y detenido en estas conclusiones, es la índole de los vínculos que el Comando del Litoral entabló con la Unión Cívica Radical. En el artículo, mostramos que los líderes del Comando estuvieron lejos de enfatizar una adscripción partidaria. Contrariamente a ello, se esforzaron por aparecer como autónomos de cualquier agrupamiento político, incluido el radicalismo. Sin embargo, a las incursiones armadas llevadas a cabo por él se las suele recordar como "intentonas radicales". ${ }^{38}$ Esto se debe, en parte, a que militantes de la UCR participaron en los diferentes levantamientos. Pero encuentra sobre todo su explicación en el hecho de que los sectores opositores al radicalismo -y

que aquí se hacen fundadas en los propósitos e intenciones que se le atribuyen a estos amigos (...) Estos de Montevideo creen que perdida Santa Fe por la consecuencia del fraude, las autoridades partidarias permitirán proceder de acuerdo con los hechos y circunstancias; pues, si vacilan y aconsejan prolongar la situación actual de espera, la disciplina se resintiría y el alzamiento se haría efectivo, ya que se posee y se tiene todo lo necesario para una acción positiva. He comprobado que en realidad se cuenta con la ayuda del exterior indispensable para estos actos". Carta de Cattáneo a Alvear, fechada en Buenos Aires el 26 de octubre de 1936 (reproducida en Botana, Gallo y Fernández, 2000: 20-23).

${ }^{36}$ Véase: "Carta de Abalos a Bosch (22 de enero de 1934)", reproducida en A. Cattáneo, 1959: 408-410.

${ }^{37}$ Véase la carta de los Hermanos Kennedy a Alvear, en Botana, Gallo y Fernández, 2000.

${ }^{38}$ Sin ir más lejos, Ana V. Persello, la autora que más sistemática y exhaustivamente ha analizado el radicalismo durante este período, se refiere a ellas como "conspiraciones radicales" (Persello, 2004: 146). 
muy particularmente las autoridades nacionales, que veían en el perdurable arraigo de la UCR en las masas el principal desafío a su legitimidad- hicieron todo lo que estuvo a su alcance para presentar a los distintos motines como "movimientos orgánicos del radicalismo personalista". Tanto Uriburu como Justo, en efecto, imputaron los distintos alzamientos sin matices ni medias tintas al radicalismo (Giménez, 2014: 104-105). Con ello, pretendían presentar ante la opinión al radicalismo en continuidad con su pasado revolucionario, desmintiendo así los supuestos avances que en cuanto a organicidad e institucionalidad interna aquél registraba bajo la conducción de Alvear.

Sin embargo, tal como vimos, el Comando del Litoral tuvo poco que ver con la estructura partidaria de la UCR. Es cierto que un número no desdeñable de dirigentes radicales colaboraron en las diversas incursiones armadas llevadas a cabo por aquél. Pero cuando se sumaban a sus filas, los militantes radicales se incorporaban a una organización militar que se regía por sus propias reglas y que tenía una jerarquía que le era específica. No actuaban entonces allí como dirigentes de un partido político, sino como soldados de una milicia rebelde. Además, lo que reviste gran relevancia, la decisión respecto al lugar, el momento y la modalidad de las acciones amadas corrió siempre por cuenta única de los líderes del Comando. Los papeles hallados en el archivo de Justo muestran que las autoridades de la UCR apenas si fueron contactadas para solicitar algún apoyo material a la causa rebelde. Nada más se esperaba de ellas. El último de los levantamientos, que coincidió con la celebración en Santa Fe de la Convención Nacional partidaria, dejó expuestos los desentendimientos y la falta de comunicación en toda su magnitud: en esa ocasión, el Comando procedió por fuera y a espaldas de la estructura formal de la UCR, lo cual despertó en quienes estaban al frente de ésta una enorme preocupación, dado que fueron ellas, $\mathrm{y}$, en rigor también, el entero partido, los que después sufrieron las consecuencias del infructuoso acto armado.

El poco esmero de los litoraleños en forjar vínculos con el radicalismo, $\mathrm{y}$, más en general, con los civiles, se entiende a partir de la concepción que predominaba en ellos acerca de que bastaba con que algunos regimientos se declararan en rebeldía para dar por tierra con el gobierno. Según su visión, era el uso de la fuerza lo que definiría el resultado de los diferentes movimientos. El apoyo que podían prestar los civiles, tanto los partidos políticos como otras organizaciones sociales, resultaba a todas luces secundario ante lo que, consideraban, efectivamente incidía en el desenlace de los acontecimientos: la movilización militar. Acorde con ello, en los diferentes bandos, proclamas y manifiestos elaborados por el Comando no se mencionaba explícitamente al radicalismo. De tal modo, sus líderes pretendían dejar en evidencia que el carácter del movimiento no era partidario -lo cual, dada la mentalidad estrechamente militar que en ellos predominaba, era sinónimo de faccioso, y, por lo tanto, estaba revestido de un rasgo de impureza- sino "patriótico": lo que buscaban, tal como aquéllos trataron de dejar siempre en evidencia, no era la reinstauración de Yrigoyen, ni tampoco el regreso del radicalismo al gobierno, sino el restablecimiento de las libertades públicas y el imperio efectivo de la soberanía popular, lo cual se alcanzaría derribando al régimen instaurado en septiembre de 1930 y delegando el poder en la Corte Suprema de 
Justicia -institución ésta que recibiría el mandato de convocar a elecciones sin fraudes ni proscripciones-. Reforzaba esa vocación no partidaria el hecho de que, ni en los documentos del Comando ni en las declaraciones de sus referentes, se vinculaba los alzamientos que ellos motorizaban con la tradición revolucionaria del radicalismo. Las gestas de 1890, 1893 y 1905 no eran citadas, en efecto, como antecedentes válidos para las incursiones armadas del Comando.

En definitiva, sin articulaciones sólidas con la sociedad, y sin el acompañamiento de otros sectores militares, las intentonas del Comando estuvieron destinadas al fracaso. El régimen conservador pudo persistir en el poder y consolidarse a tal punto que en el resto de los años treinta, pese a la creciente ilegitimidad de los gobiernos surgidos del fraude, no se volvieron a ensayar levantamientos en su contra.

\section{Referencias bibliográficas}

Baron Biza, R. 1934. Por qué me hice revolucionario. La triple alianza contra el derecho de asilo, Montevideo, Editorial Campo.

Blasi Brambilla, A. 1993. "Movimientos radicales restauradores de los años '30”. En: Historia, Buenos Aires, No. 51, Septiembre-Noviembre.

Botana, N.; Gallo, E. y Fernández, E. 2000. Serie Archivo Alvear. 3. El final de la abstención, 1934-1936, Buenos Aires, Instituto Torcuato Di Tella.

Burgos, O. 2000. Los otros Kennedy. Revolución armada llevada a cabo por los Hermanos Kennedy el 3 de enero de 1932 en La Paz, Entre Ríos, Buenos Aires, Editorial Martín.

Castelán de Fracchia, S. 1999. "La revolución de Pomar y el Territorio Nacional del Chaco". En: Nordeste, Segunda Época, No 10, Resistencia, Instituto de Historia, Facultad de Humanidades, UNNE.

Cattáneo, A. 1959. Plan 1932. El concurrencismo y la revolución (Estudio crítico y orgánico de una política argentina), Buenos Aires, Proceso Editorial.

--------. 1939. Entre Rejas. Memorias. Buenos Aires, Editorial Chango.

Cesario, R. 2004. La revolución de los Kennedy, Corrientes, Ediciones Moglia.

De Privitellio, L. 2001. "La política bajo el signo de la crisis". En: Cattaruzza, A. (Dir.) Crisis económica, avance del Estado e incertidumbre política, 1930-1943, Bs. As., Sudamericana.

--------. Agustín P. Justo. Las armas en la política, Buenos Aires, FCE, 1997.

Ezcurra, J. R. y Ezcurra, J. O. 1998. El levantamiento del 20 de julio de 1931. La lucha en Corrientes y Chaco para restablecer el Estado de Derecho, Paso de los Libres, ed. de los autores.

Fonttes, C. y Duarte, R. 2002. As Estâncias Contam a História, Santa María.

Galasso, N. 1985. Jauretche y su época, Buenos Aires, Peña Lillo Editor, 1985.

Giménez, S. R. 2014. Un partido en crisis, una identidad en disputa. El radicalismo en la tormenta argentina (1930-1945), Tesis Doctoral, Facultad de Ciencias Sociales, UBA.

Halperin Donghi, T. 2004. La república imposible (1930-1945), Buenos Aires, Ariel. 
Jauretche, A. 2011. Escritos inéditos, Buenos Aires, Corregidor. 2002. El Paso de los Libres. Relato gaucho de la última revolución radical, Bs. As., Corregidor.

Lopa, R. 2008. Los fabulosos Kennedy. Ensayo histórico de una rebelión, Bs. As., Nuevos Tiempos.

Luna, F. 1958. Alvear, Buenos Aires, Libros Argentinos.

Macor, D. 2001. "Partidos, coaliciones y sistemas de poder" En: A. Cattaruzza, Nueva Historia Argentina. Tomo VII..., op. cit.

Orona, J. V. 1966. La revolución del 6 de septiembre, Buenos Aires, sin datos de edición.

Persello, A. V. 2004. El partido radical. Gobierno y oposición, 1916-1943, Bs As, Siglo XXI.

Pomar, G. 1933. Memorias, 2 tomos, sin datos de edición.

Potash, R. 1986. El ejército y la política en la Argentina (I), 1928-1945. De Yrigoyen a Perón, Buenos Aires, Hyspamérica.

Rodríguez, Y. 1934. Los Kennedy (La gesta radical de La Paz, Entre Ríos), Edición de homenaje del Comité Nacional de la UCR.

Rouquié, A. 1986. Poder militar y sociedad politica en la Argentina, Buenos Aires, Hyspamérica.

Sánchez De Larramendy, M. 1994. "La revolución de Corrientes de 1931 vista por sus conductores”, XIV Encuentro de Geohistoria Regional, Universidad Nacional del Nordeste, Resistencia, 1994.

Villalba, M. A. 2012. La frontera en armas. Crónica de la revolución radical de 1933, en Paso de los Libres y Santo Tomé (Ctes.). Ensayo de historia oral, Corrientes, Ediciones Moglia. 